\title{
Prevalence and Risk Factors For Retinopathy of Prematurity Among Infants in Minilk-II Hospital, Addis Ababa, Ethiopia: A Retrospective Cross- Sectional Study, 2020.
}

Emebet Berhane Woldemariam ( $\nabla$ emebet.berhane@aau.edu.et )

Addis Ababa University

Hana Endale Aliyou

Addis Ababa University

Yosef Tsige Redi

Addis Ababa University

\section{Research}

Keywords: Retinopathy of prematurity, Retina, Premature, risk factors

Posted Date: January 19th, 2021

DOI: https://doi.org/10.21203/rs.3.rs-148640/v1

License: (9) This work is licensed under a Creative Commons Attribution 4.0 International License.

Read Full License 


\section{Abstract}

Background: Retinopathy of prematurity (ROP) is defined as a vaso-proliferative retinal disorder that leads to childhood blindness; and persists as the main cause of preventable childhood blindness. The impact of ROP in developing countries is heavier as term infants can develop ROP because of inadequate awareness of the disease development and the risk factors. Hence, the aim of the study is assessing the prevalence and risk factors for retinopathy of prematurity in the specific study area.

Methodology: An institutional based cross-sectional retrospective study was conducted on 301 samples of the pediatrics out-patient eye clinic medical records, at Minilik II referral hospital, from March to April 2020. Study subjects were selected using systematic random sampling method. Data was collected from medical records of all infants visiting the hospital for eye problems from January 2018 to December 2019, using a structured check list. The collected data was entered and cleaned using Epi data 6.4.2.0 and then exported \& analyzed using SPSS version 25. Bivariate and multivariate analysis was computed to distinguish the statistically significant factors.

Result: The prevalence of ROP among infants in this study showed $39(13 \%)$. Of these, more than half (56.4\%) were Zone II + Stage 1, followed by Zone II + stage-2, and Stage-5; $12.8 \%$ and $10.2 \%$ respectively. Birth weight, oxygen therapy and sepsis were the factors significantly associated with ROP [AOR=39.28; 95\% Cl: 3.204- 481.658], [AOR= 5.317; 95\% Cl:1.009- 28.019] and [AOR=9.805; 95\% Cl:1.592- 60.388] respectively.

Conclusions: the prevalence of ROP in the current study is (13\%). Birth weight, oxygen therapy and sepsis were the determinant risk factors for development of ROP. Regular ANC, and maternal education may be important to reduce the risk of low-birth weight, and sepsis that results in long-term oxygen therapy leading to childhood blindness.

\section{Background}

Retinopathy of prematurity (ROP) is defined as a vaso-proliferative retinal disorder that leads to childhood blindness; and persists as the main cause of preventable childhood blindness (1). The growth of abnormal retinal vessels secondary to incomplete vascularization of the retinal tissue that resulted from hyperoxia reduce regulation of vascular endothelial growth factor (VEGF) and death of endothelial cells. Neonates who have ROP are therefore, prone to increase visual complications, both structural and functional in extended terms. The structural complication leads to refractive errors and strabismus while functional complications results in mild to severe visual impairments such as absolute blindness, decrease contrast sensitivity, visual field defects and irregular color vision and perception $(2,3)$.

In human embryos, there are two stages by which the retina vascularized; these are vasculo-genesis and angiogenesis; and taken place within 12 to 21 weeks of the gestational age. The early stage of retinal vascularization is developed with the process of cells differentiate from endothelial progenitor into endothelial cells to form blood vessels the so called vasculogenesis then to superficial plexuses that is an 
angiogenesis stage. At beginning of the 16 weeks of gestational age the blood vessels progressively develop to spread in the retina, starting from the optic disk; hence at the gestational age 32 weeks reaching to nasal retina; and at 36 to 40 weeks the blood vessel spreads to temporal retina (4). In premature babies the maturity of retinal blood vessels is incomplete; however, the vessels possibly grow and proliferated abnormally. The grown abnormal blood vessels may easily bleed inside the plane retina; when the blood is reabsorbed by the abnormal vessels may leads to numerous bands that resemble as membrane and retinal scaring. When the retinal scare shrinks, they pull up the retina and resulting detachment of retina that leads to blindness prior to age of 6 months (5).

Retinopathy of prematurity is now rising as a significant cause of ocular morbidity in low and middle income countries (4). Furthermore, in developing countries the numbers of affected infants are usually larger because the problem can occur on infants with term gestational age than the infants in developed countries. Blindness due to ROP is largely preventable with early detection and treatment. Therefore, infant screening for ROP is the essential and a primary step in childhood blindness prevention as that tend to early treatment. The early treatment is also effective in changing the disease course and prevents blindness. Currently, ROP has gained a public attention worldwide (5). Hence, the recent United Kingdom national guidelines has recommended ROP screening, for babies of birth weight less than $1501 \mathrm{~g}$ and / or gestational age less than 32 weeks.

However, it is estimated that globally, about five million children are losing their vision permanently related to ROP each year (7). On top of that about $60 \%$ of the preterm births occur in sub-Saharan Africa and Asia. The enhancements of neonatal care in developing countries has also increased the survival rates of premature infants. Among the survived infants, many of them grow with disabilities, associated with visual complications. Furthermore, in resources limited regions currently, the incidence of ROP is higher among premature infants than the previous because of the availability of relatively improved quality neonatal care $(3,8,9)$.

The incidence rate of ROP among different countries is varying, and ranges from $26.1 \%$ to $47.2 \%(15,16$, 17). However, either incidence or prevalence rate of ROP in the study area is unknown. ROP is a multifactorial disease and caused as a result of neonatal and/or maternal risk factors. The most important neonatal risk factors are preterm delivery, especially before the $32^{\text {nd }}$ week of gestation and birth weight less than $1500 \mathrm{~g}(19)$; moreover, respiratory disorders, infection, increased oxygen $\left(\mathrm{O}_{2}\right)$ therapy, phototherapy, and receiving blood transfusion (21). Maternal risk factors include mode of delivery, diabetes, preeclampsia (20). Mostly low gestational age (GA), low birth weight (BW) and oxygen therapy with high concentration are the major ROP risk factors (18).

In developing countries, the problem related to ROP is heavier; even term infant can develop it because of inadequate awareness of the risk factors for the disease development, lack of skilled professionals and/or scarcity of resource to provide care for infants who are at risk $(10,11)$. Over the previous two decades many low and middle income countries (LMICs) have developed programs for ROP control, although many have incomplete coverage and poor coordination (12). 
ROP causes massive impacts on the quality of life of the infants such as life time visual impairment or blindness (13). Any intervention which improves quality care of a newborn can contribute in reducing the possibility for the occurrence of ROP; hence, prevention in developing countries is crucial to preserve the quality of life of the infants (14).

Therefore, parents/ caregivers of a high-risk baby for ROP should be well-informed about their baby's condition prior to discharge from the neonatal intensive care unit, as the infants require strict follow up by ophthalmologist in outpatient basis to screen ROP (6).

There was no study focusing on assessing the prevalence rate of ROP and the associated factors in the study area; therefore, this study may help to bridge a gap on understanding the magnitude of ROP and significant factors in the specific study area and provide a base line information for future researchers.

\section{Methods}

\section{Aim, design and setting of the study}

The study is carried out to assess the prevalence and risk factors of retinopathy of prematurity among infants who were attending in Minilik II referral Hospital, Addis Ababa, Ethiopia from March to April, 2020; and used an institutional based retrospective cross-sectional study design. Minilik-ll referral hospital is one of a tertiary referral hospital for eye problems and an area where subspecialty training of ophthalmology given for resident doctors in Ethiopia. Within the hospital, the ophthalmology department provides healthcare service for eye morbidity both pediatrics and adult referral cases.

\section{Study participants}

The study was conducted by reviewing medical record of 301 infants' in pediatrics outpatient department of ophthalmology who had been visiting the clinic with the time of January 2018 to December 2019. Eligible participants were selected using inclusion criteria that include all infants whose age less than 12 months old on first presentation. Those medical records of the infants with congenital abnormality including congenital eye disease were excluded.

\section{Data collection process}

The data was collected using structured checklist that comprise infant characteristics: gender, age, gestational age, birth weight and history of oxygen therapy, as well as history of infant's co-morbidities such as, apnea, respiratory distress syndrome (RDS), anemia, sepsis and others; maternal factors such as maternal age and mode of delivery, history of preeclampsia/eclampsia, diabetes mellitus, blood transfusion and length of hospital stay are included in the checklist. Study subjects' medical files were selected by a simple random sampling method using the medical recording number.

\section{Statistical analysis}


The collected data was entered in to EPI data 6.4.2.0 and exported to SPSS version 25 for analysis. A statistical analysis both descriptive and inferential analysis were computed. In descriptive analysis the proportion, mean and standard deviation were calculated; using logistic regression analysis statistically significant variables have been identified. Statistical significance was declared at $P$ value less than 0.05 .

\section{Results}

\section{Infant's characteristics}

A total of 301 infants' medical records were reviewed. Of these, reviewed records they were almost in equal gender distribution, male 150 (49.8\%) and female 151(50.2\%) infants. Regarding age on time of the first visit, about $128(42.5 \%)$ were between the age of one and six months; while $46(15.3 \%)$ were neonates (below the age of one month) and 127(42.2\%) were above six months age; details were depicted on Table 1 .

\section{Risk factors}

Regarding the risk factors both with the infants and maternal sides the study finding indicates: infant related risk factors include gestational age, birth weight and oxygen therapy. Infant's gestational age: majority $250(83.1 \%)$ of them were $\geq 32$ weeks, while the rest $51(16.9 \%)$ were $<32$ weeks gestational age. With regard to birth weight, $243(80.7 \%)$ of them were 1500gm; 49 (16.3\%) were between 1001 and $1500 \mathrm{gm}$; and $9(3 \%), \leq 1000 \mathrm{gm}$. About the infant's history of oxygen therapy, the majority $196(65.1 \%)$ were with no oxygen therapy; while 105 (34.9\%) had history of oxygen therapy. Among those who had oxygen therapy, $50(47.6 \%)$ were taking oxygen therapy for less than seven days, while $55(52.4 \%)$ of them had taken for seven and more days. In relation to maternal factors, the majority $179(59.5 \%)$ mothers were in the age range 29 to39 years. Most mothers 299(99.3\%) reported no diabetes; and 285 $(94.7 \%)$ had no preeclampsia during the pregnancy period. With regard to mode of delivery, majority (78.1\%) of the mothers gave birth by spontaneous vaginal delivery. Table 2 shows the detail.

\section{Prevalence rate and Description of retinopathy of prematurity}

Out of 301 infants who visited the pediatrics eye clinic of Minilik-II referral hospital for eye problem within one year; $39(13 \%)$ of the infants were diagnosed for retinopathy of prematurity. Among those who had ROP, the description of ROP were more than half $(56.4 \%)$ of the cases were Zone-II + Stage- 1 ; followed by Zone II + stage-2 that account 5(12.8\%); and stage-5, 4(10.2\%). Diagrammatic presentation seen on figure 1 and 2.

\section{Factors associated with retinopathy of prematurity}

To identify factors associated with retinopathy of prematurity, logistic regression model was used. Using bivariate analysis candidate variables were selected. Variables such as gestational age, birth weight, duration of oxygen therapy, preeclampsia, apnea, Respiratory Distress Syndrome (RDS), anemia, sepsis and blood transfusion were identified. In multivariate analysis birth weight, oxygen therapy and having 
sepsis during neonatal period were statistically significant. Therefore, infants with birth weight less than $1000 \mathrm{gm}, 12$ times and birth weight between 1000 and $1500 \mathrm{gm}, 39$ times more likely to develop ROP than the birth weight > $1500 \mathrm{gm}$, [AOR: 12.51; 95\% Cl (1.218-128.532)]; [AOR: 39.28; 95\% Cl (3.204481.658)], respectively. Regarding the oxygen therapy duration, infant who received oxygen during neonatal period for more than seven days were 7 times more likely for ROP than who had no oxygen therapy; [AOR: $5.317 ; 95 \% \mathrm{Cl}(1.009-28.019)]$. Those who had history of sepsis were 9 times more likely for ROP than no sepsis [AOR: $9.805 ; 95 \% \mathrm{Cl}(1.592-60.388)]$. The details depicted on Table-3.

\section{Discussion}

In this study the prevalence of retinopathy of prematurity was $13 \%$; it is lower than other studies that reported as, 41.7\%, from Kenya (20); 47.2\%, in Nigeria (15); in India, 19.2\% (22); in Egypt, 19.2\% (9); and $31.6 \%$ in China (23). This fact indicates low prevalence rate; since there was no separate ROP screening clinic the participants were picked up from the records of all infants who had eye examination in ophthalmology out-patient department. However it was higher than the study conducted in Indonesia 11.9\% (24), in Beijing 10.8\% (25), in Pakistan 10.5\% (26) and in Switzerland 9.3\% (27).

Retinopathy of prematurity is a serious morbidity of prematurity. The occurrence and severity increased with low birth weight (28). The findings of this study have also shown that birth weight had significant association with ROP. Those infants with birth weight < $1500 \mathrm{gm}$ were highly risk for ROP development. This result was in line with a study done by Freitas $M$ that shown statistical significance of extremely low birth weight for the development of ROP at $P=0.001,(16)$. Another study also showed that extremely low birth infants had 10.8 times more risk to develop ROP than that of not low birth weight (24). Additionally, another study done by Onyango 0 et al showed that birth weight had significant association with the occurrence of ROP ( $P=0.027)(20)$. Besides, another study done in India by Dwivedi described that birth weight had independent risk factors for the occurrence of ROP $(P=0.02)(29)$. Another study done by Arjumand Sohaila in a Tertiary Care Hospital in a Lower-Middle Income Country Pakistan showed that birth weight $(P=0.037)$ was an independent risk factor for the occurrence of ROP (26). Furthermore, study done in Palestine by Akkawi mentioned that birth weight had a significant association for the development of ROP with a significant value of $\mathrm{P}=0.0085(30)$. Moreover, a study done in India by $\mathrm{R}$,Nikil showed that birth weight was a significant factor for the incidence of ROP ( $P=0.001)$ (22). In China, Yunxia Lengin Guangzhou First People's Hospital also described that birth weight was a significant factor for the development of ROP $(P=0.009)(23)$.

However, finding of this study was different from some studies done in Egypt by Hakeem et al and Nigerian by Adedayo 0 , had shown that birth weight was insignificant for ROP development $(15,31)$. This can happen because of the studies were using small number sample size; therefore, the result could be different.

The result of this study has shown that oxygen therapy for more than seven days had been significant for ROP development $(P=0.049)$. Similarly study done by F. Mutangana et al. (32), Akkawi (30), and by Cut 
Badriah (24); had also shown that oxygen therapy had significant association for the development of $\operatorname{ROP}(p<0.05)$.

Additionally, neonatal sepsis, in this study were significant factor for the development of ROP with $(P=0.014)$. This finding is in line with studies done by Hakeem et al, (31), by Cesarina Borroni in Italy (34); further more studies in Turkey (54) and in Nigeria (15) were reporting that sepsis was a significant factor for ROP development.

However, the finding of this study was unlike with study in Indonesian and Kenya the finding revealed that sepsis was not a significant risk factor for $\operatorname{ROP}$ development $(20,24)$. The reason behind might be as the impact of sepsis and hospital acquired infection can be determined by the quality of care provided in neonatal intensive care unit, so sepsis is insignificant in these areas. Whereas, in the current study area due to the limited resource, the quality of the care in NICU is not as such advanced so sepsis becomes significant factor.

Generally, this study showed that birth weight and oxygen therapy were a major risk factors and sepsis was a co morbidities factor. A systemic review and a meta-analysis study in Iran showed that birth weight, oxygen therapy and sepsis were a significant risk factors for retinopathy of prematurity (35).

\section{Conclusion}

The prevalence of ROP in the current study is (13\%). Birth weight, oxygen therapy and sepsis were the determinant risk factors for development of ROP. Regular ANC, and maternal education may be important to reduce the risk of low-birth weight, and sepsis that results in long-term oxygen therapy leading to childhood blindness.

\section{Abbreviations}

BW: Birth Weight, GA: Gestational Age, LMICs: Low-and Middle- Income Countries, MOH: Ministry of Health, NICU: Neonatal Intensive Care Unit, RDS: Respiratory Distress Syndrome, ROP: Retinopathy of Prematurity, SPSS: Statistical Package for Social Science, $T_{1}$ ROP: Type one Retinopathy of Prematurity, VEGF: Vascular Endothelial Growth Factor, VLBW: Very Low Birth Weight, FDRE: Federal Democratic Republic Ethiopia.

\section{Declarations}

\section{Ethics approval and consent to participate}

Ethical approval was obtained from institutional review board (IRB) of Addis Ababa University, College of Health Sciences, School of Nursing and Midwifery; with the reference protocol number: 016/220/SNM and meeting number: 09/2012 EC. Permission letter obtained from the office of Minillik-II referral hospital. Since the study was a retrospective study, informed consent was exempted; according the FDRE National 
Research Ethics Review Guideline. Confidentiality of the data that obtained from the medical files of the children was maintained de-identified by coding anonymously.

\section{Consent for publication}

Not applicable

\section{Availability of data and materials}

The datasets generated and/or analyzed during the current study are available in Addis Ababa University repository.

\section{Competing interests}

The authors declare that they have no competing interests

\section{Funding}

No fund has been provided from the outside resources.

\section{Author contribution}

A.H.E, R.Y.T and W.E.B, conceived the research idea, and involved in the design. While A.H.E, involved in field work, data analysis and report writing, R.Y.T and W.E.B, participated in the overall supervision and manuscript preparation. All authors have reviewed and approved the final version of the manuscript.

\section{Acknowledgments}

We acknowledge Minilik-II referral hospital, outpatient record office staffs and data collectors for their support. Finally, our gratitude goes to Dr Asrat Demtse (Neonatologist), Dr Sadik Taju (ophthalmologist) and Dr Miserak Tadesse (Neonatologist) for their contribution with professional advises throughout the research process.

\section{Authors' information}

Hana E. Aliyou, (RN, MSC in Pediatrics and Child health Nursing and MSc in Neonatal Nursing). She has more than 7 years' experience of Neonatal nursing. Currently, she is working in Neonatal Intensive Care Unit, at Tikur Anbessa Specialized Hospital, Addis Ababa University, Ethiopia. Email:

aliyouhana@gmail.com

Emebet B. Woldemariam, (RN, MSc in Adult Health Nursing and PhD fellow). She has both the clinical (ophthalmic nurse) and academic (teaching and research) experience. Currently, she is working in School of Nursing and Midwifery, College of Health Sciences, Addis Ababa University, Ethiopia with the position of Lecturer. Email: emebetbw@gmail.com, 
Yosef T. Redi, (RN, MSc in Nursing), has more than 20 years' experience in teaching and research. He has published numbers of scientific articles in reputable journals as author and co-author. Currently, he is working in School of Nursing and Midwifery, College of Health Sciences, Addis Ababa University, Ethiopia with the position of Assistant Professor. yosief.tsige@aau.edu.et; yosieftsige8@gmail.com

\section{References}

1. Mutlu FM SS. Treatment of retinopathy of prematurity:a review of conventional and promising new therapeutic options Int J Ophthalmol. 2013;6(2):228-36.

2. Blencowe $\mathrm{H}$, al. e. Born too soon:the global epidemiology of 15 million preterm births reprod health. 2013;10(1).

3. Beharry KD VG, Lazzaro DR, Aranda JV. Pharmacologic interventions for the prevention and treatment of retinopathy of prematurity. Semin Perinatol. 2016;40:189-202.

4. Dave HBea. The societal burden of blindness secondary to retinopathy of prematurity in Lima, . Am J Ophthalmol. 2012;154(4):750-5.

5. Rastriya_Bal_Swaasthya_Karyakram. Child health screening and early intervention services Health andFamilyWelfare. underNRHMMinistry ofHealth and FamilyWelfare. 2013.

6. Fierson WM. Screening examination of premature infants for retinopathy of prematurity. Pediatrics. 2013;131(1):189-95.

7. Gilbert C. Retinopathy of prematurity a global perspective of the epidemics, population of babies at risk and implications for control. Early Hum Dev. 2008;84:77-82.

8. Sommer A, Taylor HR, Ravilla TD, al. e. Challenges of ophthalmic care in the developing world. Ophthalmol. 2014;132:640-4.

9. Abdel HA. Retinopathy of prematurity:a study of incidence and risk factors in NICU of Al-Minya University Hospital in Egypt. J Clin Neonatol. 2012;2(1):76.

10. Uhumwangho OM, YT. I-A. Awareness and screening for retinopathy of prematurity among paediatricians in Nigeria. J West Afr Coll Surg. 2013;3(3):33.

11. Chaudhry TA, Hashmi FK, Salat MS, al. e. Retinopathy of prematurity: an evaluation of existing screening criteria in Pakistan. Ophthalmol. 2014;98:298-301.

12. Aremsen L, Duran P, Silva J, Brumana LA. cross-sectional observational study of retinopathy of prematurity in Latin America and the Caribbean Revista Panamerica de Salud Publica. 2016;39:3229.

13. Courtright P HA, Lewallen $S$. Visual impairment in children in middle- and lower-income countries. Arch Dis Child. 2011;96(12):1129-34.

14. Srinivas Murki SK. Role of neonatal team including nurses in prevention of ROP. COMMUNITY EYE HEALTH JOURNAL. 2018; 31.

15. Adedayo AO RU, Chidi NG,Augusta EU. Retinopathy of prematurity in Port Harcourt, Nigeria... ISRN Ophthalmol. 2014. 
16. Freitas AM, Mörschbächer R, Thorell MR, EL. R. Incidence and risk factors for retinopathy of prematurity: a retrospective cohort study. Int J Retina Vitreous. 2018;20(4).

17. Maroufizadeh S, Almasi-Hashiani A, Omani Samani R, Sepidarkish M. Prevalence of retinopathy of prematurity in Iran: a systematic review and meta-analysis. Int J Ophthalmol. 2017;10(8):1273-9.

18. Liegl R, Hellström A, LE. S. Retinopathy of prematurity: the need for prevention. Eye Brain. 2016;91(8):102.

19. Senthil MP SM, Bujang MA, et al. Risk factors and prediction modelsfor retinopathy of prematurity. Malays J Med Sci. 2015;22(5).

20. Onyango 0 ea. Retinopathy of prematurity in Kenya: prevalence and risk factors in a hospital with advanced neonatal care. Pan Afr Med J. 2018;29(152).

21. Edy Siswanto J SP. Retinopathy of prematurity in Indonesia: Incidence and risk factors. Neonatal Perinatal Med. 2017;10(1):85-90.

22. R. Nikhil, K. Rajendran, Krishnan. B. Prevalence and outcome of retinopathy of prematurity in preterm infants, with low birth weight at $\mathrm{KMCH}$, Tamil Nadu, India. International Journal of Contemporary Pediatrics. 2019 6(2).

23. Yunxia $L$, et al. . The treatment and risk factors of retinopathy of prematurity in neonatal intensive care units BMC Ophthalmology 2018;301(18).

24. Cut Badriah ea. Prevalence and risk factors of retinopathy of prematurity. Paediatr Indones. 2012;52(3).

25. Chen Y LX-x, Yin H, Gilbert C, Liang JH, Jiang YR, et al. . Risk factors for retinopathy of prematurity in six neonatal intensive care units in Beijing, China. . Br J Ophthalmol.92:326-30.

26. Arjumand Sohaila ea. Frequency of Retinopathy of Prematurity in Premature Neonates with a Birth Weight below 1500 Grams and a Gestational Age Less than 32 Weeks: A Study from a Tertiary Care Hospital in a Lower Middle Income Country. plusone. 2014;9( 7).

27. Gerull R, al. e. Incidence of retinopathy of prematurity (ROP) and ROP treatment in Switzerland 20062015: a population-based analysis. Child Fetal Neonatal 2018;103(4):337-42.

28. Bas AYea. Incidence, risk factors and severity of retinopathy of prematurity in Turkey (TR-ROP study): a prospective, multicentre study in 69 neonatal intensive care units. $\mathrm{Br} \mathrm{J}$ Ophthalmol 2018;102:1711-6.

29. Dwivedi ea. Prevalence, risk factors and pattern of severe retinopathy of prematurity in eastern Madhya Pradesh. Indian Journal of Ophthalmology. 2019;67(6).

30. Mohammad T. Akkawi MMS, Amjaad N. Abu Shams3, Doaa M. Al-Hardan3, Lara J. Omar, Omar H. Almahmoud and Jamal A. S. Qaddumi. Incidence and risk factors of retinopathy of prematurity in three neonatal intensive care units in Palestine. BMC Ophthalmology. 2019;189(19).

31. H. A. A. Hakeem GBM, and M. F. Othman,. "Retinopathy of prematurity: a study of prevalence and risk factors,Middle East African Journal of Ophthalmology,. 2012.; 19,(3,):289-94,. 
32. Francis Mutangana ea. Retinopathy of prematurity in Rwanda: a prospective multi-centrenstudy following introduction of screening and treatment services The Royal College of Ophthalmologists. 2019;34:847-56.

33. Lee J DO. Perinatal infection, inflammation, and retinopathy of prematurity. Semin Fetal Neonatal Med. 2012;17:26-9.

34. Borroni. Survey on retinopathy of prematurity (ROP) in Italy. Italian Journal of Pediatrics. 2013; 43(39).

35. Milad Azami, et a. Prevalence and risk factors of retinopathy of prematurity in Iran: a systematic review and meta-analysis BMC Ophthalmology 2018;18(83).

\section{Tables}

Table 1: Scio-demographic characteristics of study participants in Minilik II referral Hospital, Addis Ababa, Ethiopia, 2020

\begin{tabular}{|llll|}
\hline Variable & Category & Frequency $(\mathrm{n}=301)$ & Percent \\
\hline \multirow{3}{*}{ Infant's age } & $<1$ month & 46 & 15.3 \\
\cline { 2 - 4 } & $1-6$ months & 128 & 42.5 \\
\cline { 2 - 4 } Gender & $6-12$ months & 127 & 42.2 \\
& Male & 150 & 49.8 \\
\cline { 2 - 4 } Maternal Age & Female & 151 & 50.2 \\
\cline { 2 - 4 } & 29-28yrs & 112 & 37.2 \\
\cline { 2 - 4 } & $\geq 40 \mathrm{yrs}$. & 179 & 59.5 \\
\cline { 2 - 4 } & & & 3.3 \\
\hline
\end{tabular}

Table 2: Risk factors for retinopathy of prematurity in Minilik II referral Hospital, Addis Ababa, Ethiopia, 2020 


\begin{tabular}{|c|c|c|c|}
\hline \multicolumn{4}{|l|}{ Infant related risk factors } \\
\hline Variable & Category & Frequency $(n=301)$ & Percent \\
\hline \multirow[t]{2}{*}{ Gestational age } & $\geq 32$ & 250 & 83.1 \\
\hline & $<32$ & 51 & 16.9 \\
\hline \multirow[t]{3}{*}{ Birth weight } & $<1000 \mathrm{gm}$ & 9 & 3 \\
\hline & $1001-1500 \mathrm{gm}$ & 49 & 16.3 \\
\hline & $>1500 \mathrm{gm}$ & 243 & 80.7 \\
\hline \multirow[t]{2}{*}{ Oxygen therapy } & Yes & 105 & 34.9 \\
\hline & No & 196 & 65.1 \\
\hline \multirow[t]{2}{*}{ Duration of oxygen therapy $(n=105)$} & $<7$ days & 50 & 47.6 \\
\hline & $>7$ days & 55 & 52.4 \\
\hline \multicolumn{4}{|l|}{ Maternal related risk factors } \\
\hline \multirow[t]{2}{*}{ Maternal Diabetes mellitus } & Yes & 2 & 0.7 \\
\hline & No & 299 & 99.3 \\
\hline \multirow[t]{2}{*}{ Maternal preeclampsia } & Yes & 16 & 5.3 \\
\hline & No & 285 & 94.7 \\
\hline \multirow[t]{4}{*}{ Mode of delivery } & SVD & 235 & 78.1 \\
\hline & CS & 62 & 20.6 \\
\hline & Vacuum & 1 & 0.3 \\
\hline & Forceps & 3 & 1.0 \\
\hline
\end{tabular}

$\mathrm{SVD}=$ Spontaneous vaginal delivery; $\mathrm{CS}=$ cesarian section; $\mathrm{gm}=\mathrm{Grams}$

Table 3: Factors associated with ROP on study conducted in Minilik II referral Hospital, Addis Ababa, Ethiopia, 2020 


\begin{tabular}{|c|c|c|c|c|c|}
\hline \multirow[t]{2}{*}{ Variables } & \multicolumn{2}{|l|}{ ROP } & \multirow{2}{*}{$\begin{array}{l}\mathrm{p}- \\
\text { value }\end{array}$} & \multirow[t]{2}{*}{ COR $(95 \% \mathrm{Cl})$} & \multirow[t]{2}{*}{ AOR $(95 \% \mathrm{Cl})$} \\
\hline & Yes & No & & & \\
\hline \multicolumn{6}{|l|}{ Birth weight } \\
\hline$\leq 1000 \mathrm{gm}$ & $8(20.5 \%)$ & $1(0.4 \%)$ & 0.034 & $\begin{array}{l}11.600(1.344- \\
100.3)\end{array}$ & $\begin{array}{l}12.5(1.218- \\
128.532) *\end{array}$ \\
\hline $1001-1500 \mathrm{gm}$ & $\begin{array}{l}20 \\
(51.3 \%)\end{array}$ & $29(11 \%)$ & 0.004 & $\begin{array}{l}168.7(19.36- \\
1470.45)\end{array}$ & $\begin{array}{l}39.28(3.204- \\
481.658)^{\star *}\end{array}$ \\
\hline$>1500 \mathrm{gm}$ & $11(28.2 \%)$ & 232(88.5\%) & & 1 & 1 \\
\hline \multicolumn{6}{|c|}{$\begin{array}{l}\text { Duration of oxygen } \\
\text { therapy }\end{array}$} \\
\hline$<7$ days & $12(30.8 \%)$ & $38(14.5 \%)$ & & & \\
\hline$\geq 7$ days & $24(61.5 \%)$ & $31(11.8 \%)$ & 0.049 & $\begin{array}{l}20.31(5.47- \\
75.452\end{array}$ & $\begin{array}{l}5.317(1.009- \\
28.019)^{\star}\end{array}$ \\
\hline Had no oxygen & $3(7.7 \%)$ & 193(73.7\%) & & 1 & 1 \\
\hline \multicolumn{6}{|l|}{ Sepsis } \\
\hline Yes & $37(94.9 \%)$ & $63(24 \%)$ & 0.014 & $\begin{array}{l}58.43(13.6- \\
249.32)\end{array}$ & $\begin{array}{l}9.805(1.592- \\
60.388) *\end{array}$ \\
\hline No & $2(5.1 \%)$ & 199(76\%) & & 1 & 1 \\
\hline
\end{tabular}

*Statistically significant; ** Highly Statistically significant

\section{Figures}

\section{Prevalence of ROP}

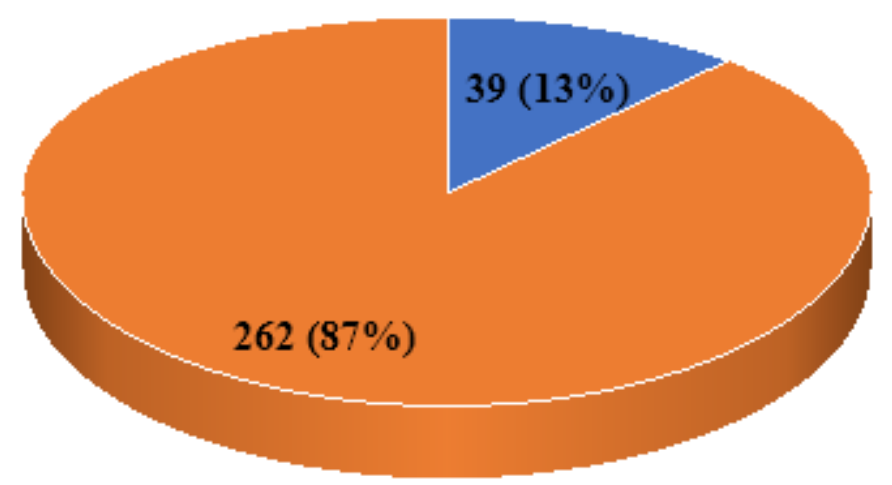

$$
\text { - Yes - No }
$$

Figure 1 
Prevalence of retinopathy of prematurity among infants in Minilik II Hospital in Addis Ababa, Ethiopia, 2020

\section{Description of ROP}

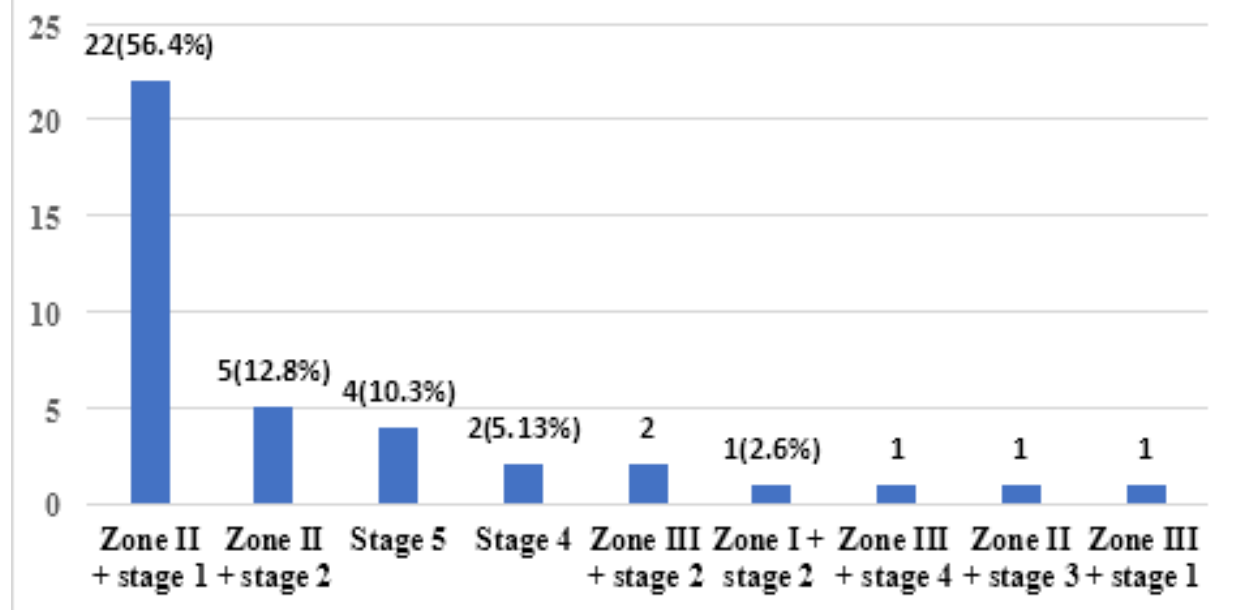

\section{Figure 2}

Description of retinopathy of prematurity among infants in Minilik II Hospital in Addis Ababa, Ethiopia, 2020 